\title{
GENETIC COUNSELING FOLLOW-UP - A RETROSPECTIVE STUDY WITH A QUANTITATIVE APPROACH
}

\author{
João M. De Pina-Neto' ${ }^{1}$ and Eucia Beatriz L. Petean ${ }^{2}$
}

\begin{abstract}
The impact of genetic counseling (GC) was evaluated in families, who were interviewed at least two and half years and at most seven years after GC at the Genetics Service of the University Hospital, Faculty of Medicine of Ribeirão Preto, University of São Paulo (HC, FMRP, USP). The 113 families interviewed in this study were asked 48 questions and all children born after GC were studied clinically. We evaluated the families for spontaneous motivation for GC and understanding of GC information, their reproductive decisions, changes in the family after GC and the health status of new children. The majority of families seen at the Hospital das Clínicas de Ribeirão Preto were not spontaneously motivated to undergo GC. They had a low level of understanding about the information they received during GC. Generally families were using contraceptive methods (even when at low genetic risk) with a consequent low rate of pregnancies and children born after GC. These families also had a very low rate of child adoption and divorces when compared to other studies.
\end{abstract}

\section{INTRODUCTION}

In 1969, the Human Genetics Committee of the World Health Organization recommended that genetic counseling programs perform "genetic counseling follow-up investigations to determine the behavior of counselees" (WHO, 1969). The data obtained in these studies help counselors improve the effectiveness of the genetic counseling that they provide for the community, and this new contact with counselees becomes a valuable complement of genetic counseling (GC) sessions (Abramovsky et al., 1980). Evaluation of medical services based on clinical practice results is recognized today as an essential step in medicine (Delamothe, 1994).

Since the early seventies, several studies have been conducted to evaluate GC in different countries. Some concerned a single disease such as phenylketonuria (Sibinga and Friedman, 1971), Duchenne muscular dystrophy (Emery et al., 1972) and mucoviscidosis (McCrae et al., 1973). Others concerned a small group of diseases such as mucoviscidosis, phenylketonuria, Down syndrome (Leonard et al., 1972), and congenital heart disease (Reiss and Menashe, 1972), or more frequently, groups of different types of disease, since most GC services indiscriminately handle all types of genetic disease (Carter et al., 1971; Emery et al., 1973; Reynolds et al., 1974; Klein and Wyss, 1977; Briard et al., 1977; Abramovsky et al., 1980). Some reviews (Shaw, 1977; Evers-Kiebooms and van den Berghe, 1979) have emphasized difficulties in comparing the data obtained due to methodological differences among the various services both in the form and the objectives of

${ }^{1}$ Departamento de Genética, Faculdade de Medicina de Ribeirão Preto, Universidade de São Paulo, Av. Bandeirantes, 3900, 14049-900 Ribeirão Preto, SP, Brasil. Send correspondence to J.M.P.-N. Fax: +55-16-633-0069. E-mail: jmdpneto@fmrp.usp.br

${ }^{2}$ Departamento de Psicologia, Faculdade de Filosofia, Ciências e Letras de Ribeirão Preto, Universidade de São Paulo, Ribeirão Preto, SP, Brasil.
GC, as well as in the evaluation of results. Shaw (1977) also expressed concern about geneticists' inadequacy in executing the operational phase of this work, since they are not trained in social or behavioral work. She also stated that evaluation, in order to be objective, should not be performed by the counselor himself.

The general objective of the present study was to evaluate a sample of families counseled at the Genetics Outpatient Clinic of the University Hospital of Ribeirão Preto, University of São Paulo, in order to understand the impact of GC on these families, and their objective and subjective reactions to the occurrence of genetic diseases, especially regarding their later reproductive life. Specific objectives were to evaluate: a) level of understanding (or recall) of $\mathrm{GC}, \mathrm{b})$ attitudes taken by the couple, especially with respect to family planning, c) knowledge, acceptance and use of contraceptive and abortive methods, d) reproductive life of counselees after GC, e) health status of children born after GC, and f) influence of factors such as socioeconomical and cultural level and religion on counselee behavior.

\section{MATERIAL AND METHODS}

\section{Subjects}

\section{Sample selection criteria}

1) Time interval between GC and follow-up interviews: families seen between two and a half and seven years after GC. 2) Types of disease: families with children affected by genetic, multifactorial or correlated (syndromes of unknown etiology) diseases.

\section{Sample characterization}

One hundred and thirteen families that fulfilled the above criteria were studied. Families were seen at the Medi- 
cal Genetics Service of the University Hospital, Faculty of Medicine of Ribeirão Preto, University of São Paulo, and corresponded to $17 \%$ of the families seen during the study period. This sample included 54 different types of diseases: Down syndrome (39.8\%), Duchenne muscular dystrophy (3.5\%), achondroplasia, sickle-cell anemia and Marfan syndrome (2.6\% each), congenital adrenal hyperplasia, Prader-Willi syndrome, trisomy 13, ectrodactyly, Laurence-Moon syndrome and phenylketonuria $(1.8 \%$ each), and 43 other types of diseases involving only one family. Eighty-four percent of the 113 families presented subjects affected by genetic diseases, $46 \%$ of which were chromosomal diseases and $38 \%$ monogenic diseases; $3.5 \%$ were diseases of multifactorial etiology, $9.8 \%$ were diseases of unknown etiology, and $2.7 \%$ were diseases of heterogeneous etiology for which it was not possible to establish the exact cause of the disease. Among the chromosomal diseases, Down syndrome due to free trisomy 21 was the most frequent $(35.4 \%$ of the total sample and $76.9 \%$ of the chromosomal diseases). Five families had chromosome translocations (4\% of the total sample and $9.6 \%$ of the chromosomal diseases), with four inherited translocations and one de novo translocation. Among the monogenic diseases, the most frequent was autosomal recessive disease $(18.5 \%$ of the total sample and $48.8 \%$ of the monogenic diseases), followed by dominant diseases (13.2\% of the total sample and $34.9 \%$ of the monogenic diseases) and X-linked recessive diseases (5.4\% of the total sample and $13.9 \%$ of the monogenic diseases). In the sample studied, $48.7 \%$ of the fathers, $64.6 \%$ of the mothers and $56.5 \%$ of the couples were 34 years of age or less. Among the propositi, $83.1 \%$ were 12 years old or less, and only $2.7 \%$ were older than 20 . Risk of recurrence was low (considered to be less than 10\%) for most of the families studied $(63.7 \%) ; 31.8 \%$ of the families were at high risk, and $4.5 \%$ had doubtful risk due to etiologic heterogeneity (variations in the causal mechanism).

We determined whether the family had sought GC, i.e., whether or not it was spontaneously motivated, and found that most families $(69 \%)$ had been referred for diagnosis and/or did not even know what Genetics is, i.e., they were not spontaneously motivated for GC; $23.9 \%$ of the families went to the service specifically to find out if they were at risk to have children with genetic disease, i.e., they were spontaneously motivated for GC. Families in the present sample were markedly concentrated in the lower social strata: $85 \%$ were classified as belonging to classes E, D and C; only 7\% were classified as B and $8 \%$ as A. With respect to religion, most families $(86.5 \%)$ declared themselves to be Roman Catholic, 9.5\% were Protestant, 2\% Spiritualist, and 1\% simply Christian. Among the mothers, $1.9 \%$ stated that they had no religion, and the number of Spiritualist fathers (3.6\%) was slightly higher than the number of Spiritualist mothers (1.0\%). Most families declared that they did not practice their religion $(63.6 \%)$, with mothers stating that they practiced their re- ligion more than fathers (45.2\% versus $25.4 \%)$. However, even among mothers the number of non-practicing subjects was higher $(54.8 \%)$. In general, both parents were present during the GC interviews (61\%) and the GC follow-up interview (69\%). However, many times the mother attended the sessions alone (34.5\% of the GC interviews and $25.7 \%$ of the follow-up interviews). The father was present alone in a much smaller number of families (3.6\% of the GC interviews and $5.3 \%$ of the GC follow-up interviews).

\section{Methods}

\section{Data Survey}

a) A special form was developed based on previous GC follow-up studies, especially those of Carter et al. (1971), Leonard et al. (1972), Emery et al. (1972) and Reynolds et al. (1974), as well as the form developed by the Brazilian Center of Analysis and Planning (CEBRAP) for human reproduction studies (Berquó and Camargo, 1977; Berquó et al., 1977). The form consisted of 48 questions covering the general objectives of the study. Sections I, II and III concerned family identification. Section IV concerned data about family income, occupation, educational level, religion and importance of religion for the parents. Section V aimed to determine the level of understanding of the information provided during GC. Section VI questioned how the disease affected the reproductive behavior of the individual, the role risk of recurrence played in reproductive decisions and level of acceptance of adoption. Section VII concerned knowledge and use of contraceptive methods, acceptance of abortion methods in cases of severe fetal disease, and parents' interpretation of their religion's opinion of abortion, and section VIII evaluated the reproductive life of the couple after the GC process, i.e., whether they had children, if pregnancy was planned, if children were born during the study period (the children that were born were all evaluated clinically), whether they adopted children, if there were changes in the sexual behavior of the couple as a function of the problem they were facing, and whether the couple separated.

b) Application of the form: parents from the selected families were interviewed at the Genetics Outpatient Clinic of the University Hospital, FMRP, USP. The interview was conducted by a main interviewer (a psychologist) and a secondary interviewer (a physician). Parents were interviewed jointly when possible, or separately if parents came on different days or only one spouse responded to the call. The duration of each interview was approximately $1 \mathrm{~h}$ and $30 \mathrm{~min}$.

c) Clinical examination of the children born after GC: all children born after GC were examined and photographed.

\section{Data analysis}

a) Social stratification: socioeconomic stratifica- 
tion was established based on family income, father's or substitute father's occupation and father's or substitute father's educational level by the method of Guidi and Duarte (1969). This method establishes a weight system for the three variables, attributing points for each stratum of each variable. The final score was: $\mathrm{E}$ stratum (lowest) $=$ 13 to 22 points; $\mathrm{D}$ stratum $=23$ to 34 points; $\mathrm{C}$ stratum $=$ 35 to 44 points; B stratum $=45$ to 55 points and A stratum (highest $)=56$ to 65 points .

b) Evaluation of spontaneous motivation for GC: families that sought counseling at the Genetics Service and verbally expressed their concern about possible risks of disease repetition in other family members were considered to show spontaneous motivation. Families looking for help who only expressed their concern about diagnosis and/or treatment, or families simply referred without awareness of the purpose of the visit were considered not to have spontaneous motivation.

c) Evaluation of understanding level: GC understanding was classified into three levels. A base level, called satisfactory understanding level, was assigned to people who were aware of the risk of disease repetition in his/her family, since the major objective of GC is to inform about the risk of recurrence. An adequate level was assigned to those who, in addition to being aware of the risk, also knew the cause of the disease in the family (etiology) and the treatment required. An inadequate level was assigned to people who were unaware of the magnitude of risk, expressed verbally in the simplest form.

d) Evaluation of responses about causes and risks of disease repetition: we classified the responses according to the basis of the response. A - Scientific, when the responses were based on scientific laws and principles, with an A+ score when the scientific principle was correctly employed and an A- score when the scientific principle was incorrectly employed. B - Mystical or religious, when the responses were based on religious principles. C Popular belief, when the responses were based on folkloric culture. D - Anti-scientific, when the responses contested scientific principles without formulating any other explanation for the disease in the family. E - Empirical, when the responses were based on a trial and error process, with false deductions (e.g., the doctor said that this is due to age, but there are other women of my age who have normal children). F - Syncretic, when the responses were based on two or more of the above principles. $\mathrm{G}$ - unable to explain.

e) Classification of contraceptive methods: to facilitate analysis we classified contraceptive methods based on the degree of ease of access. 1 - Medical, methods that require medical intervention for their use, i.e., intrauterine devices (IUD), tube ligation and ligation of the vas deferens. 2 - Paramedical, methods produced by an industrial process but that do not necessarily require medical guidance and/or intervention for their use in Brazil, i.e., contraceptive pills, condoms, diaphragms, vaginal suppositories and gel. 3 - Popular, methods that do not need medical guidance, are not produced by an industrial process and are popularly known and used, such as douching, coitus interruptus, sexual abstinence, rhythm and breast-feeding.

\section{Statistical analysis}

Data were analyzed statistically by the chi-square test, using contingency tables.

\section{RESULTS}

\section{Evaluation of spontaneous motivation for genetic counseling}

Most (74\%) of the families studied were not spontaneously motivated to seek GC. There was a clear relationship between the family's social level and spontaneous motivation for GC. The frequency of spontaneous motivation was low for the lowest social levels $(E=1 / 35)$, and progressively increased for higher social levels $(\mathrm{D}=$ $8 / 36 ; C=6 / 17 ; B=5 / 7 ; A=7 / 9)$. These differences were significant $($ chi-square $=166.5, \mathrm{P}<0.01)$.

\section{Evaluation of GC understanding level}

Analysis revealed a predominantly inadequate understanding level in our sample (48.7\%), with much lower frequencies of satisfactory $(28.8 \%)$ and adequate $(22.5 \%)$ understanding levels. Understanding level did not differ significantly between fathers and mothers (chi-square = 0.15). On the other hand, the interview played a clear role in the determination of understanding level, especially among fathers, with significant differences at the $1 \%$ level between fathers alone and fathers accompanied by the mother (chi-square $=23.3$ ), and significant differences at the 5\% level between mothers alone and mothers accompanied by the father (chi-square $=8.0$ ). Understanding of mothers alone was significantly better than that of fathers alone (chi-square $=8.9 ; \mathrm{P}<0.05$ ), whereas the understanding of accompanied fathers was similar to that of accompanied mothers (chi-square $=0.55$ ). This clearly shows that the understanding (or verbalization) of fathers alone was worse, and that the father's performance improved when he was accompanied by his wife. Thus, there is an induction of response, especially in the woman-man direction.

Many parents identified the risk of repetition only as being low or high both in groups classified as having adequate understanding (37.2\%) and satisfactory understanding $(51.7 \%)$. The proportion of subjects aware of the risk who mentioned the probability in a correct manner was $34.9 \%$ in the adequate group and $13.8 \%$ in the satisfactory group. The number of subjects who overestimated or underestimated the risk was similar in the two groups.

When the basis of the inadequacy of the responses was evaluated in terms of risk of repetition, we observed that most $(66.6 \%)$ of the people considered to have inad- 
Table I - Distribution of families in terms of level of understanding of genetic counseling and social stratification.

\begin{tabular}{|c|c|c|c|c|c|c|c|c|c|c|c|c|}
\hline \multirow{3}{*}{ Understanding } & \multicolumn{10}{|c|}{ Social stratification } & & \\
\hline & \multicolumn{2}{|c|}{ E } & \multicolumn{2}{|c|}{ D } & \multicolumn{2}{|c|}{$\mathrm{C}$} & \multicolumn{2}{|c|}{ B } & \multicolumn{2}{|c|}{ A } & \multicolumn{2}{|c|}{ Total } \\
\hline & No. & $\%$ & No. & $\%$ & No. & $\%$ & No. & $\%$ & No. & $\%$ & No. & $\%$ \\
\hline Adequate & 7 & 16.3 & 10 & 23.2 & 5 & 11.6 & 7 & 16.3 & 14 & 32.5 & 43 & 22.5 \\
\hline Inadequate & 32 & 74.4 & 35 & 38.0 & 19 & 20.6 & 5 & 5.4 & 1 & 1.1 & 92 & 48.2 \\
\hline Satisfactory & 25 & 44.6 & 21 & 37.5 & 7 & 12.5 & 0 & 0.0 & 3 & 5.3 & 56 & 29.3 \\
\hline
\end{tabular}

* Based on Guidi and Duarte (1969); for details see Material and Methods; A is the highest level.

equate understanding levels had a distorted understanding of the risk of repetition, while $23 \%$ knew nothing about the risk of repetition, and $10.4 \%$ gave responses that contradict the scientific principles involved in the formulation of the risk of repetition.

Analysis of the relationship between understanding level and time elapsed between the GC interview and the follow-up interview showed a clear time effect. Knowledge about genetic diseases in their families became worse with time: the frequency of inadequate understanding was $28.2 \%$ after a 2-3-year interval between interviews, 59.8\% after a 3-5-year interval and $61.2 \%$ after a 5-7-year interval. On the other hand, the frequency of adequate understanding was $37.2 \%$ for a 2-3-year interval, $11.3 \%$ for a 35 -year interval, and $27.7 \%$ for a 5-7-year interval, and the frequency of satisfactory understanding was $34.6 \%$ for a 2-3-year interval, $28.9 \%$ for a 3-5-year interval, and $11.1 \%$ for a 5-7-year interval. These differences are significant at the $1 \%$ level (chi-square $=39.6$ ).

There was no significant difference in the inadequate group in terms of presence or absence of spontaneous motivation for GC. In contrast, differences were clear in the group with adequate understanding (36\% with spontaneous motivation and $19.5 \%$ with no spontaneous motivation) and in the group with satisfactory understanding, in which the frequency of people with spontaneous motivation was lower (14\%) than the frequency of individuals without spontaneous motivation (35.2\%). Presence or absence of spontaneous motivation for GC did not seem to be important for the understanding of the risk of repetition, but it was important to understand the remaining problems of the propositus (disease, cause, etc.).

Adequate understanding was clearly related to family social class, with an increase from $11 \%$ for class $E$ to $77.7 \%$ for class A (Table I). In the group with satisfactory understanding there was a decrease from class E (39\%) to class B $(0 \%)$. Although an increase to $16.8 \%$ was observed in class $\mathrm{A}$, the general trend of a decreasing frequency of this understanding level with higher social classes was maintained. In the group with inadequate understanding there was an increase from class $\mathrm{E}(50 \%)$ to class $\mathrm{C}$ $(61.3 \%)$, with a slight decrease in class B $(41.6 \%)$ and a marked decrease in class A $(5.5 \%)$. The differences in understanding level according to social class were significant at the $1 \%$ level $($ chi-square $=188.8)($ Table I) .

The frequency of individuals who explained the disease at a scientific level was highest $(51.3 \%)$, with a correct interpretation in 33\% (A+) and an incorrect interpretation in $18.3 \%$ (A-). These groups were followed by those who did not know how to explain the disease (36.2\%), and those who explained it on the basis of popular belief $(7.3 \%)$, syncretism $(3.3 \%)$, religion $(1.0 \%)$, or anti-scientifically $(0.5 \%)$ (Table II). It is interesting to note the small number of people who explained the disease based on religious principles (1.0\%), although part of these people were included in the syncretism group (also at a low frequency). These differences were significant at the $1 \%$ level $($ chi-square $=192.5$ and 17.4) .

The group with adequate understanding of GC consisted solely of subjects who based their understanding on a scientific explanation. Most had a correct interpretation (95.3\%) and the remaining ones had an incorrect interpretation (4.7\%). Most subjects in the group with inadequate understanding could not explain the information provided during GC (43\%), followed by an explanation at the scientific level (39.7\%), $29.0 \%$ with an incorrect interpretation and $10.7 \%$ with a correct interpretation, by popular belief $(9.7 \%)$, syncretism $(5.4 \%)$, and religion $(2.2 \%)$. The distribution in the group with satisfactory understanding was similar to that of the inadequate group, although there was a larger number of people who could not explain the cause of the disease $(52.7 \%)$. Nobody explained the disease at the

Table II - Levels of explanation of the cause of the disease compared to genetic counseling understanding level in the families studied.

\begin{tabular}{|lrrrrrrrrr|}
\hline & \multicolumn{8}{|c|}{ Levels of explanation* } & \\
\cline { 2 - 7 } Level & A+ & A- & B & C & D & E & F & G & TOTAL \\
\hline Adequate & 41 & 2 & 0 & 0 & 0 & 0 & 0 & 0 & 43 \\
Inadequate & 10 & 27 & 2 & 9 & 0 & 0 & 5 & 40 & 93 \\
Satisfatory & 12 & 6 & 0 & 5 & 1 & 0 & 2 & 29 & 55 \\
\hline
\end{tabular}

* A+ = Scientific explanation correctly employed; A- = scientific explanation incorrectly employed; $\mathrm{B}=$ mystic or religious explanation; $\mathrm{C}=$ popular belief-based explanation; $\mathrm{D}=$ anti-scientific explanation; $\mathrm{E}=$ empirical explanation; $\mathrm{F}=$ syncretic explanation; $\mathrm{G}=$ unable to explain. 
religious level (as observed in the group with adequate understanding), and $1.8 \%$ of the people explained it at a nonscientific level. No person was classified as level E (empirical).

Evaluation of the effect that social level had on how well the individual could explain the cause of the disease showed a sharp correlation between these variables: the frequency of A+ explanation decreased from $88.8 \%$ in class A to $18.5 \%$ in class E; for an incorrect scientific explanation (A-) there was an increase in frequency from $0.0 \%$ in class A to $24.6 \%$ in class $\mathrm{E}$; at the $\mathrm{B}, \mathrm{C}, \mathrm{D}$ and $\mathrm{F}$ levels the frequency increased with lowering of social class; at the $\mathrm{G}$ level (could not explain) the frequency increased until class $C(46.6 \%)$ and then decreased to $36.2 \%$ in class $\mathrm{E}$, which, however, was much higher than class $\mathrm{A}(11.2 \%)$. When the explanation levels of the disease cause were evaluated with respect to how religious the parents were, a scientific level was observed in $60.5 \%$ of those who declared a high degree of religiousness and in $44.4 \%$ of those who declared a low degree of religiousness. Religion played no role in determining $\mathrm{B}, \mathrm{C}, \mathrm{D}$ and $\mathrm{F}$ explanation levels. At the G level (could not explain) $23.9 \%$ were very religious, and $44.5 \%$ were relatively unreligious.

\section{Evaluation of parental reproductive decision}

The evaluation of parental reproductive decision revealed: a) a large number of couples decided not to have children regardless of risk ( $64.4 \%$ of the total sample), which was a decision of both fathers $(65.5 \%)$ and mothers $(63.5 \%)$; b) more high-risk couples $(85.7 \%)$ decided to avoid having children than low-risk ones (52.9\%). This difference was significant at the $1 \%$ level (chi-square $=$ 28.9317). However, a large number of people at low risk also decided to avoid having children, whereas the number of people at high risk who decided to have children was small $(7.9 \%)$; c) there was no significant difference between the total number of fathers and mothers who decided to avoid having children regardless of the magnitude of risk; d) understanding among high-risk parents was significantly different at the $1 \%$ level when the father or mother attended the session alone compared to when the father and mother came together. More couples that attended sessions together decided not to have more children than those that attended alone; e) in cases of low risk, these differences were not statistically significant (Table III).

Table III - Reproductive decision and risk of disease repetition according to family interview.

\begin{tabular}{|c|c|c|c|c|c|c|c|}
\hline & Father & Mother & Accomp. & Accomp. & \multicolumn{2}{|c|}{ Total } & Total \\
\hline & alone & alone & father & mother & Father & Mother & \\
\hline & \multicolumn{7}{|c|}{ High risck } \\
\hline To avoid & $\begin{array}{c}\text { No. } \\
4\end{array}$ & $\begin{array}{l}\text { No. } \\
10\end{array}$ & $\begin{array}{l}\text { No. } \\
20\end{array}$ & $\begin{array}{l}\text { No. } \\
20\end{array}$ & $\begin{array}{l}\text { No. } \\
24\end{array}$ & $\begin{array}{l}\text { No. } \\
30\end{array}$ & $\begin{array}{l}\text { No. } \\
54\end{array}$ \\
\hline Not to avoid & 1 & 0 & 2 & 2 & 3 & 2 & 5 \\
\hline No decision* & 1 & 3 & 0 & 0 & 1 & 3 & 4 \\
\hline \multirow[t]{2}{*}{ Total } & 6 & 13 & 22 & 22 & 28 & 35 & 63 \\
\hline & \multicolumn{7}{|c|}{ Low risk } \\
\hline To avoid & 7 & 13 & 21 & 22 & 28 & 35 & 63 \\
\hline Not to avoid & 6 & 14 & 14 & 13 & 20 & 28 & 48 \\
\hline No decison* & 1 & 2 & 3 & 3 & 4 & 5 & 9 \\
\hline \multirow[t]{7}{*}{ Total } & 14 & 29 & 38 & 38 & 52 & 68 & 120 \\
\hline & & & & & & \multicolumn{2}{|c|}{ General total } \\
\hline & & & & Decision & Father & Mother & Total \\
\hline & & & & To avoid & $\begin{array}{l}\text { No. } \\
55\end{array}$ & $\begin{array}{l}\text { No. } \\
68\end{array}$ & $\begin{array}{c}\text { No. } \\
123\end{array}$ \\
\hline & & & & to avoid & 24 & 30 & 54 \\
\hline & & & No & lecision* & 5 & 9 & 14 \\
\hline & & & & Total & 84 & 107 & 191 \\
\hline
\end{tabular}

*The father and/or mother had already been submitted to definitive sterilization or were not of reproductive age; disagreeing couples: high risk $=1$ (mother alone: to avoid; father alone: not to avoid); low risk $=2$ (mother alone: not to avoid; father alone: to avoid); 2 accompanied father: accompanied mother: to avoid; $\chi^{2}$ (total high risk $\mathrm{x}$ total low risk $)=28.9317$ ( $\mathrm{P}<0.01 ; 2$ d.f.); $\chi^{2}$ (low risk - fathers as a whole $\mathrm{x}$ mothers as a whole $=0.0679$ (NS; 2 d.f.). $\chi^{2}$ (high risk - fathers as a whole $\mathrm{x}$ mothers as a whole) $=3.5736$ (NS; 2 d.f.); $\chi^{2}$ (high risk - father alone $\mathrm{x}$ accompanied father $)=22.6879\left(\mathrm{P}<0.01 ; 2\right.$ d.f.); $\chi^{2}$ (high risk - mother alone $\mathrm{x}$ accompanied mother $)=33.3681$ ( $\mathrm{P}<0.01 ; 2$ d.f.). $\chi^{2}$ (low risk - father alone $\mathrm{x}$ accompanied father $)=$ 0.7515 (NS; 2 d.f.); $\chi^{2}$ (low risk - mother alone $x$ accompanied mother) $=4.1040$ (NS; 2 d.f.). 
When the decision to avoid children was considered with respect to the level of GC understanding without a distinction between those who made the decision specifically because of the risk and those who made the decision for other reasons, no significant differences were detected between the various understanding levels, as follows: high risk - decision to avoid children - adequate understanding $=88.2 \%$, inadequate understanding $=91.6 \%$, satisfactory understanding $=100 \%$; low risk - decision to avoid children - adequate understanding $=65.2 \%$, inadequate understanding $=50.0 \%$, satisfactory understanding $=65.6 \%$. Thus, the differences between high and low risk observed in Table I were maintained.

There was a clear correlation between understanding of the risk and motivation of the decision to avoid having children (Table IV): among those at a high risk, 93.7\% of those with adequate understanding and $100 \%$ of those with satisfactory understanding stated that their decision was due to the risk. On the other hand, in subjects with inadequate understanding $54.5 \%$ stated that they would avoid having children due to the risk, while $45 \%$ said they would avoid having children due to other reasons. In cases of low risk, the frequency of subjects with adequate or satisfactory understanding who decided to avoid having children for other reasons (66.6\% and $68.2 \%$, respectively) was significantly higher $($ chi-square $=13.2, \mathrm{P}<0.01$ ) than the frequency of subjects who decided to avoid having children because of the risk $(33.3 \%$ and $31.8 \%$, respectively). Among subjects with an inadequate understanding, the frequency of those who stated they would avoid having children due to the risk, even though it was low, was much higher $(80 \%)$.

\section{Evaluation of acceptance and use of contraceptives}

A major problem that limited the evaluation of acceptance and use of contraceptives in this sample was the fact that there were no clear records of the contraceptive methods used by the families before GC.

The analysis of the contraceptive use in the families showed (Table V): a) regardless of the risk of repetition, the contraceptive pill was the method most extensively used by families (26.3\%), followed by tubal ligation $(16.5 \%)$, coitus interruptus $(15.5 \%)$ and condoms $(8.7 \%)$; b) among low-risk cases, about $20 \%$ of the families did not use any contraceptive method, while in cases of high risk, all couples used contraceptives; c) the difference between high- and low-risk families influenced the medical methods of birth control (IUD $=2.9 \%$ versus $1.6 \%$; tubal ligation $=26.5 \%$ versus $12.5 \%$; vasectomy $=5.9 \%$ versus $0 \%$ ). No significant differences were observed with respect to paramedical and folk methods. No significant differences in access to the various contraceptive methods were observed among the different social classes.

When we evaluated the importance of religion on contraceptive use, $40.6 \%$ felt that their religion is entirely against the use of contraceptive methods, $35.8 \%$ felt that their religion is fully in favor, $15.5 \%$ felt that their religion does not express an opinion on their use, $4.4 \%$ felt that their religion is in favor of responsible contraceptive use, and $3.7 \%$ felt that their religion is against their use but permits some exceptions.

When we evaluated the acceptance of definitive sterilization as a reproductive decision, we observed that: a) in high-risk cases, fathers who decided not to avoid hav-

Table IV - Reason for the decision to avoid pregnancy (due to the risk or not), risk of repetition and understanding level of genetic counseling in the families studied.

\begin{tabular}{lccc|}
\hline & YES & NO \\
& & High risk & \\
& No. & No. \\
& 15 & 1 \\
Adequate & 12 & 10 \\
Inadequate* & 15 & 0 \\
Satisfactory & & Low risk & \\
& No. & & No. \\
& 5 & & 10 \\
Adequate & 20 & 5 \\
Inadequate* & 7 & 15 \\
Satisfactory & &
\end{tabular}

Yes = Individuals who declared that they avoid pregnancy because of the risk. No $=$ Individuals who declared that they avoid pregnancy due to other reasons. *There were 2 fathers alone, 2 mothers alone, and 1 accompanied father and 1 accompanied mother who had discordant opinions. $\chi^{2}$ (Yes high $\mathrm{x}$ low $)=44.9098(\mathrm{P}<0.01 ; 2$ d.f. $) . \chi^{2}($ No - high $\mathrm{x}$ low $)=102.0091$ ( $\mathrm{P}<0.01 ; 2$ d.f.).

Table V - Contraceptive methods currently used by the families studied according to risk of repetition of genetic defect.

\begin{tabular}{|c|c|c|c|c|}
\hline \multirow[t]{3}{*}{ Method } & \multicolumn{4}{|c|}{ Risk of repetition } \\
\hline & \multicolumn{2}{|c|}{ High } & \multicolumn{2}{|c|}{ Low } \\
\hline & No. & $\%$ & No. & $\%$ \\
\hline 1. Douching & 1 & 2.9 & 2 & 3.1 \\
\hline 2. Jelly & 0 & 0.0 & 0 & 0.0 \\
\hline 3. Vaginal suppository & 0 & 0.0 & 0 & 0.0 \\
\hline 4. Diaphragm & 0 & 0.0 & 0 & 0.0 \\
\hline 5. Rhythm & 2 & 5.9 & 2 & 3.1 \\
\hline 6. Coitus interruptus & 5 & 14.8 & 11 & 17.2 \\
\hline 7. Condom & 3 & 8.8 & 6 & 9.4 \\
\hline 8. IUD* & 1 & 2.9 & 1 & 1.5 \\
\hline 9. Contraceptive pill & 9 & 26.5 & 17 & 26.5 \\
\hline 10. Tubal ligation & 9 & 26.5 & 8 & 12.5 \\
\hline 11. Vasectomy & 2 & 5.8 & 0 & 0.0 \\
\hline 12. Abstinence & 0 & 0.0 & 1 & 1.6 \\
\hline 13. Breast-feeding & 0 & 0.0 & 0 & 0.0 \\
\hline 14. A combination of 2 or 3 methods & 2 & 5.8 & 3 & 4.7 \\
\hline 15. None & 0 & 0.0 & 13 & 20.3 \\
\hline Total & 34 & 100.0 & 64 & 100.0 \\
\hline Not determined & \multicolumn{2}{|c|}{3} & \multicolumn{2}{|r|}{7} \\
\hline
\end{tabular}

* IUD = Intra-uterine devices. 
ing children do not accept vasectomy. Of those who decided not to have more children $47.8 \%$ accept vasectomy. These differences are significant at the $1 \%$ level (chi-square $=62.8)$; b) only $24 \%$ of the fathers who decided to avoid having children and $21.1 \%$ of those who decided not to avoid having them declared that they would accept a vasectomy (nonsignificant difference); c) the difference in acceptance of vasectomy between high- and low-risk couples are significant at the $1 \%$ level (accept - chi-square $=28.9$; does not accept - chi-square $=6.8838$ ); d) in highrisk cases, $78.6 \%$ of the mothers who decided to avoid having children and $50 \%$ of those who decided not to avoid having them declared that they would accept tubal ligation (a significant difference at the $1 \%$ level - chi-square $=$ 17.8 ); e) in low-risk cases, $67.6 \%$ of the mothers who decided to avoid having children and $57.7 \%$ of those who decided not to avoid having them declared that they would accept tubal ligation (nonsignificant difference - chi-square $=2.09)$; $\mathrm{f}$ ) neither acceptance nor rejection of tubal ligation differed significantly between high- and low-risk women.

We observed that the acceptance or rejection of vasectomy among fathers was not related to the degree of religiousness. Among women there was a nonsignificant trend for greater acceptance of tubal ligation among very religious subjects and those accompanied by their husband during the interview. In general, the women of our sample wished to ligate their tubes. We also observed a relationship between high risk of recurrence and acceptance of definitive sterilization and a less marked relationship between low risk of recurrence and acceptance of definitive sterilization.

\section{Evaluation of the acceptance of abortion}

In the present sample, $66.5 \%$ of the fathers and $74.5 \%$ of the mothers felt that their religion is entirely against abortion; $9.5 \%$ of the fathers and mothers as a whole felt that their religion is entirely in favor of abortion; 5.8\% felt that their religion does not express an opinion, and the remaining parents felt that their religion accepts abortion depending on the reason for it.

High-risk couples accepted abortion better $(57.1 \%)$ than low-risk ones $(39.6 \%)(\mathrm{P}<0.05)$, with acceptance being higher among fathers alone $(71.4 \%)$ and accompanied fathers $(61.9 \%)$ than among mothers alone (53.8\%) and accompanied mothers (50.0\%) in the high-risk group. Among the mothers, a significant difference at the 5\% level was observed between the high- and low-risk groups only for those that were alone during the interview. We also observed that the risk of repetition was more important for acceptance or rejection of abortion than the degree of religiousness, since in the high-risk group practicing fathers accepted abortion more frequently $(85.7 \%)$ than non-practicing fathers (57.15) and $68.7 \%$ of practicing mothers accepted abortion. In low-risk cases there was a predomi- nance of fathers and mothers who did not accept abortion, regardless of whether they practiced their religion, or not.

\section{Evaluation of the change in family composition after GC and health of the children born}

With respect to the changes in family composition after GC and the risk of repetition, we observed that: a) the high-risk group had a significantly larger (chi-square $=158.2 ; \mathrm{P}<0.01)$ number of families in which no change in composition occurred (79.5\%) compared to families at doubtful risk (60\%) and families at low-risk (56.1\%); b) high-risk families had fewer children (five children born in 36 families) compared to low-risk families (22 children born and two additional pregnancies during the evaluation from 72 families); c) only three children were adopted, all by high-risk families.

When we analyzed the number of children born, reproductive decision and risk of disease repetition (Table VI) we observed: a) $83.3 \%$ of the children born were from low-risk families, with $61.9 \%$ of the parents having decided not to avoid pregnancy, $19 \%$ to avoid having children, and $2.4 \%$ in which only the father had decided to avoid having children; b) $4.8 \%$ of the children born were from couples at doubtful risk, with $2.4 \%$ of parents having decided to avoid pregnancy and $2.4 \%$ of families in which only the father had decided to avoid having children.

With respect to the health of children born after GC, we observed that repetition of the disease of the propositus occurred only in high-risk cases. In one family considered at genetic counseling in the low-risk group, we discovered later that the father was affected. The father has Marfan syndrome, and his four children and the proposita also have Marfan syndrome. We consider this family for analysis of recurrence of the disease in the highrisk group, and this fact explains why we considered for this analysis the 9 cases instead of the 5 cases born from the families originally considered in high-risk group. Then, in the high-risk group, among the 9 children that were born 4 were affected and all affected children belonged to the

Table VI - Combined number of children born after genetic counseling, reproductive decision and risk of disease repetition in the families studied.

\begin{tabular}{|lcccr|}
\hline & \multicolumn{4}{c|}{ No. of children/risk } \\
\cline { 2 - 5 } Decision & High & Low & Doubtful & Total \\
\hline To avoid & 3 & 8 & 1 & 12 \\
$\begin{array}{l}\text { Not to avoid } \\
\text { Discordant } \\
\text { father decided to avoid) }\end{array}$ & 1 & 26 & 0 & 27 \\
$\begin{array}{l}\text { Discordant } \\
\text { (mother decided to avoid) }\end{array}$ & 1 & 1 & 1 & 2 \\
Total & 5 & 35 & 2 & 1 \\
\hline
\end{tabular}


same sibship. In low-risk cases, there was no repetition of the disease of the propositus, but other types of health problems concerning the children born occurred in four families: isolated ear malformation, complex congenital heart disease, congenital hypotonia of undefined cause, and congenital hypotonia, probably due to neonatal hypocalcemia.

\section{Evaluation of acceptance and use of adoption}

With respect to the acceptance of adoption, we observed that: a) most people declared that they did not accept adopting a child (59.1\%); b) this rejection of adoption was higher among low-risk people $(70.3 \%)$ than among high-risk people (50\%); c) the frequency for women accepting adoption was always higher than that of men, independent of the magnitude of the repetition risk; d) the frequency of mothers alone who declared to accept adoption was higher than the frequency of accompanied mothers, whereas no important difference in acceptance of adoption was observed between fathers alone and accompanied fathers. Only two high-risk families adopted children, two children in one family and one child in the other.

\section{Evaluation of couple separation or changes in their sexual relationship}

Two couples separated. Both were at low risk for repetition.

With respect to changes in the sexual relationship of the couples after the birth of the propositus and magnitude of the risk of disease repetition we observed that: a) most people declared that there was no change in their sexual relationship; b) the frequency of people who declared that there were changes in their sexual relationship was lower (father $=15.4 \%$, and mother $=16.9 \%$ ) among low-risk couples than among high-risk couples (father = $35.7 \%$, and mother $=34.3 \%$ ); c) only in high-risk cases there was a considerable difference in the frequency of fathers alone who declared that there was no change (50.0\%) compared to accompanied fathers (31.8\%).

\section{DISCUSSION}

\section{Sample}

We defined two and a half years as the minimum time between the GC consultation and follow-up interview to select families for this study, since reproductive behavior is the most objective parameter that can be evaluated in GC follow-up studies (Shaw, 1977). Two and a half years is enough time for families to have had another child (Carter et al., 1971; Emery et al., 1973). Maximum time between GC consultation and follow-up interview varies widely in the literature, ranging from about 28 years (Klein and Wyss, 1977) to about seven years, which was the maximum interval for our sample.
In the present study, we only selected families whose propositus was affected by genetic or correlated diseases, since our aim was to study the objective and subjective reactions of families to the occurrence of a genetic disease in a relative. Studies also based on these criteria are available in the literature (Carter et al., 1971; Emery et al., 1973; Briard et al., 1977), as well as studies in which all families that received GC were evaluated indiscriminately (Reynolds et al., 1974; Klein and Wyss, 1977) and studies in which the nature of the sample was not clearly described (Abramovsky et al., 1980).

Parental age in our sample was slightly different compared to the distribution reported by Berquó and Camargo (1977) among couples of reproductive age with a stable union living in the city of São Paulo, especially in terms of father's age. In our sample, the frequency of fathers aged up to 29 years was $31.0 \%$, as opposed to only $17.7 \%$ in the São Paulo sample. This tendency for younger fathers in our sample was also observed for mothers, although less marked, with a $41.6 \%$ frequency of mothers aged up to 29 years compared to $37.7 \%$ for the São Paulo mothers. Thus, parents in our sample were mostly young, and most propositi were children aged up to 12 years $(83.1 \%)$.

In our sample there was a predominance of families at low genetic risk (63.7\% as opposed to $31.8 \%$ highrisk families), a fact also observed in all studies reported in the literature, i.e., $40.8 \%$ high-risk families and 59.5\% low-risk in the series of Carter et al. (1971), and 28.5\% high-risk families and $71.5 \%$ low-risk families in the series of Reynolds et al. (1974).

Income distribution of our sample compared to the 1980 IBGE census (IBGE, 1980) showed that our counselees were in a better socioeconomic situation compared to the country in general, but in a lower situation compared to the income distribution in the municipality of Ribeirão Preto reported by Mussia and Pereira (1980).

The educational level of our counselees was slightly higher than that detected by Berquó and Camargo (1977) in the municipality of São Paulo, with this difference being slightly more marked among women than men. When the educational level of our counselees is compared to that reported by Andrade and Pereira (1979) for the municipality of Ribeirão Preto, the situation is the same, i.e., our counselees have a higher educational level.

When we compare our sample to social stratification described by Andrade and Pereira (1979) in the municipality of Ribeirão Preto our sample had a higher frequency of parents or substitute in the lowest classes $(\mathrm{E}+$ $D)$, a higher frequency in class $C$, and a similar frequency in the higher classes $(\mathrm{A}+\mathrm{B})$. When we compare our sample to the São Paulo State sample (Berquó and Camargo, 1977) our sample had more people classified as lower class and a slightly lower frequency of upper class individuals. A dissociation between educational level and family income and a higher relationship between occupation and family income were demonstrated in our sample. 
By comparing the distribution of our sample in terms of religion to the IBGE census (1980) for the Brazilian population, we can see a slightly lower frequency of Catholics $(86.5 \%$ for our sample versus $88.9 \%$ for Brazil as a whole) and a higher frequency of Protestants $(9.5 \%$ versus $6.6 \%$ ) and Spiritists (2.0\% versus $1.3 \%)$. The same differences are detected when comparing the present sample to that studied by Berquó and Camargo (1977) in the municipality of São Paulo, with a slightly lower number of Catholics and a reasonably higher number of Protestants. When comparing our sample to that of Berquó and Camargo (1977) in terms of the degree of religiousness, the frequency of highly religious subjects (= practicing) was slightly lower in our sample (36.4\% versus $43.0 \%$ for the São Paulo sample).

\section{Spontaneous motivation}

Our sample included families that sought counseling at the Genetics Service motivated by the risk of recurrence (considered to have spontaneous motivation), those that sought counseling for other reasons (such as diagnosis) or were simply referred. The reason for this procedure was to evaluate the importance of this factor in the GC process and its determinants. Carter et al. (1971), Emery et al. (1972) and Abramovsky et al. (1980) selected their samples among people who sought counseling exclusively because of the risk of recurrence. Reynolds et al. (1974) reported that only $26 \%$ of the people in their sample sought counseling on their own, whereas all others were referred. However, the primary interest of $57 \%$ was to find out if abnormalities could be transmitted to their future children. Most of the remaining people listed this concern as secondary. In our sample the total number of people who verbally expressed worries about the risk was very low (23.9\%), with a highly significant correlation between spontaneous motivation for GC and social level, i.e., the higher the social level, the greater the desire to receive $\mathrm{GC}$ for the fear of having another child with similar problems.

\section{Understanding level of GC}

In the present study, an adequate understanding level was observed in only $22.5 \%$ of the families and a satisfactory level in $28.8 \%$. Therefore, if we consider that the main objective of GC is understanding the risk of recurrence, only $51.3 \%$ of the families verbalized this risk in a correct manner. This understanding level is one of the lowest in the literature. Clarke et al. (1996) stated that studies published in European and American literature usually show a good level of understanding or recall of the information. Somer et al. (1988) reported in Finland that 80\% of the families had a correct knowledge of the mode of inheritance and $74 \%$ of the risk of recurrence. Reynolds $e t$ al. (1974) detected adequate understanding in $84 \%$ of their sample, with $28 \%$ of them knowing the risk exactly and $72 \%$ knowing whether it was high or low, and the remaining $16 \%$ presenting distortions or rejection of the information. Abramovsky et al. (1980) found that $91 \%$ remembered the diagnosis, $72 \%$ remembered the correct percentage of risk and $56 \%$ remembered the mode of inheritance, i.e., $68 \%$ remembered the diagnosis and the risk and only $40 \%$ remembered the diagnosis, the risk and the mode of inheritance. However, studies showing a low understanding level of GC have also been published. To illustrate, Sibinga and Friedman (1971), in a study of parents of children with phenylketonuria, found that only $19 \%$ had an adequate understanding of GC information, and Reiss and Menashe (1972), in a study of parents of children with congenital heart disease conducted one to four months after the authors had reinforced the information, noted that none knew about the risk before the reinforcement, and that only $25 \%$ knew about the risk after the reinforcement. Furthermore, $38.5 \%$ knew the name of the disease of their child before the reinforcement, and only $48.6 \%$ learned it after the reinforcement. Leonard et al. (1972), in a study of families with members affected by phenylketonuria, mucoviscidosis and Down syndrome, detected imperfect understanding of genetic information in $44 \%$ of the sample. In the present study we observed that understanding level depended on the characteristics of the interview, i.e., a significant induction of a response occurred from mother to father, with the mother's presence improving the performance of the father. The only study in which sex-based (father and mother) differential understanding was evaluated was by Sibinga and Friedman (1971) with respect to phenylketonuria. These investigators showed that women understood better than men and also that the understanding of one member of the couple may compensate for the lack of understanding of the other. They also observed that the better the understanding of the mother, the better the development of the child.

In the category of adequate understanding, 34.9\% of the individuals verbalized the risk using the correct percentage, $7.0 \%$ overestimated the percentage and $2.3 \%$ underestimated the risk. If we compare these data with those reported by Emery et al. (1972) considering the exact understanding of the risk, the difference is very high since these investigators found that $84.4 \%$ of their sample knew the percentage of risk. In the category of inadequate understanding, our sample showed a predominance of distortions $(66.6 \%)$ followed by people who had no knowledge $(23.0 \%)$ and finally by rejection $(10.4 \%)$. The only paper citing the basis of inadequate responses is that by Reynolds et al. (1974) in which $16 \%$ of the individuals distorted or rejected the information, with two people actually rejecting the entire GC experience.

In our study, the time interval between $\mathrm{GC}$ consultation and follow-up interview had a significant effect on understanding level. Thus, what we call understanding level is not only understanding, but also the extent of re- 
call, since there was a decrease in the frequency of adequate and satisfactory understanding and an increase in inadequate understanding level with time interval. Both were statistically significant (chi-square $=39.6$ ). Only Reynolds et al. (1974) studied this factor in terms of the frequency of different understanding levels. They found no effect of time (example for understanding adequate: less than two years $=80 \%$; two to five years $=84 \%$; more than four years $=84 \%$ ). In contrast, in the present sample this factor contributed to a reduction of adequate and satisfactory understanding level and to an increase in inadequate understanding.

Another factor that decisively affected our sample in terms of reducing adequate understanding in favor of satisfactory understanding was spontaneous motivation (Table I). Considering this variable, there was a significant difference in adequate understanding level between those who were spontaneously motivated and those who were not (Yes $=36 \%$; No $=19.5 \%)$. Paradoxically, this difference did not favor inadequate understanding (where the frequency of Yes $=50.8 \%$ was practically identical to the frequency of No $=45.3 \%$ ), but rather satisfactory understanding, which was more frequent among those without spontaneous motivation (Yes $=14 \%$; No $=35.2 \%$ ). Reynolds et al. (1974) also detected a correlation between adequate understanding level and source of referral to the GC service (which would be equivalent to what we would call spontaneous motivation). Those who sought the service on their own had a better understanding level ( 23 of 26 had adequate understanding) than those who were referred ( 5 of 24 had adequate understanding). However, as discussed earlier, there was a strong correlation between spontaneous motivation and social stratification of the families in our sample (chi-square $=166.5$ ). Based on these data and on those listed in Table I, we may conclude that low socioeconomic-cultural level was the major factor reducing the level of GC understanding in our sample. Even in the US, Reynolds et al. (1974) showed a correlation between social class and understanding level, with an adequate understanding level in $91 \%$ of subjects belonging to classes I, II and III, and only a $68 \%$ level in classes IV and V. Other variables evaluated, such as level of recurrence risk and interview characteristics, were not important.

Thus, the fundamental factor in the reduction of understanding level in our sample was socioeconomiccultural level, followed by time interval between the GC consultation and the follow-up interview. Spontaneous motivation was a reflex of socioeconomic-cultural level.

\section{Levels of explanation of the cause and risk of repetition of the disease}

None of the studies available in the literature concerned the levels of explanation of the cause and risk of repetition of the diseases. We found it to be of fundamen- tal importance, especially under the conditions of Third World countries. In these countries, underdevelopment causes marked social differences and enhances the nature of the doctor-patient relationship as a social class relationship. Adequacy of GC techniques in underdeveloped countries must necessarily be based on a better knowledge of folk culture, especially in terms of the health-sickness dyad and its position with respect to official medical practice and its interrelations with folk medicine (Boltanski,1979).

The basis for parent's explanation of the disease frankly depended on the social class to which they belong, clearly showing that the frontiers of penetration of scientific medicine really meet a barrier in the popular strata (Table II). Among these classes, there is less penetration of scientific medicine, more persistence of folk medicine and, causing even more concern, a large number of people who do not know how to explain what happened in their family. Why did this occur? Most of this lack of understanding is probably due to inhibition in the presence of the doctor, who represents the "master of learning, and the upper classes". People of lower socioeconomic level do not empathize with the doctor and therefore hide their feelings and thoughts. A much worse possible situation would be that these ignorant people are "lost". They lost the folk medicine with which they identified and were unable to learn about scientific medicine due to their living conditions. The higher frequency of explanations with a scientific foundation among those who declared themselves very religious and the absence of an explanation based on religious principles may reflect the evolution of the Catholic Church in terms of a greater acceptance of scientific principles, since most of those who were religious in our sample declared themselves Catholics.

\section{Reproductive decision}

The present study confirmed previous reports, i.e., the risk of repetition of a genetic disease is important in the reproductive decisions of the couple, since fathers alone, mothers alone, accompanied mothers and fathers and the couples as a whole were significantly more prone to decide not to have children in a high-risk situation compared to a low-risk situation. A previously unrecorded observation was that in the high-risk case, both the father and mother, when present together, stated much more frequently their decision to avoid having children than when they were alone. However, due to the large number of people who decided to avoid having children regardless of the risk of repetition ( $64.4 \%$ of the total sample), including low-risk couples $(52.9 \%)$, other factors must influence the decision to avoid having children in addition to the risk of repetition. A certain correlation between understanding level and decision to avoid having children because of the risk was detected in our study (Table II), emphasizing the importance of understanding the risk in making reproductive decisions. This is especially appar- 
ent when the reproductive decision is compared only to understanding level without taking into account the reason for the decision to avoid having children, with no important differences between the various understanding levels in terms of the decision.

Evaluation of the degree of religiousness clearly showed that this variable had no effect on the reproductive decision of the couples. This aspect had been previously emphasized by Berquó et al. (1977), who stated that "religion per se does not represent an important factor in the determination of reproductive behavior, with all data indicating that the population studied does not present religious reasons as a foundation in this determination. The attenuation of the specific influence of religion in reproductive behavior reveals a doctrinal accommodation probably as a function of economic and social factors. Although religion is not an irrelevant factor, its influence on fecundity is permeated by the social condition of its followers."

When social class and risk of repetition were analyzed in relation to reproductive decision, the risk of repetition was found to be more important than the socioeconomic-cultural level of the individuals for their reproductive decisions, since almost all high-risk couples decided to avoid having children, regardless of their social class. However, socioeconomic-cultural level is important since high-risk couples who decided not to avoid having children belonged to class $\mathrm{D}$, and low-risk class A people decided more frequently not to avoid having children, while the other classes had a predominance of people who decided to avoid having children. We believe that these differences among the various classes in low-risk cases reflect the understanding level (which is lower in the lowest classes) and ultimately the socioeconomic-cultural level of the individuals.

We observed that the number of existing children is important in the decision to avoid having more children in all social classes: among childless couples the predominant decision was not to avoid pregnancy regardless of the risk, whereas the decision to avoid having children increases with the number of existing children in all social classes. However, risk is more important than the number of existing children or social level for the reproductive decision: among childless high-risk couples the predominant decision was to avoid pregnancy in both classes A and $\mathrm{E}$, whereas class $\mathrm{D}$ couples with children decided more frequently to avoid having children. Most low-risk couples decided to have at most two children. After the second child, most couples decided not to have more children regardless of their social class.

Between number of existing children and social class, the former was clearly more important for reproductive decisions. This is a fact that in reality must reflect the latter, since change in the concept of ideal family size is linked to the current life situation which affects all social classes. The prominent role that risk of repetition had in changing the concept of ideal family size was clearly observed when we analyzed the number of children before $\mathrm{GC}$, the risk of repetition and the reproductive decision. Analysis showed that family size becomes much more limited in high-risk cases than in low-risk ones (a significant difference at the $1 \%$ level; chi-square $=28.6484$ ). The question of the ideal family size exists, because in the present study low-risk couples with two to four children often decided to avoid pregnancy regardless of social class. As demonstrated by Berquó et al. (1977) in the municipality of São Paulo, the ideal family size was three children $(38.7 \%)$, followed by two children $(20.2 \%)$ and four children $(17.9 \%)$.

The importance of the risk of repetition for reproductive decisions of couples at genetic risk has been shown by several investigators (Carter et al., 1971; Emery et al., 1972; Reynolds et al., 1974; Klein and Wyss, 1977; Abramovsky et al., 1980). The influence of religion, number of children before GC, social class and ideal family size has never been previously studied.

\section{Acceptance and use of contraceptives}

Only four of the 113 families had never used any contraceptive method (low-risk families who decided not to avoid pregnancy), and 13 families were not using any contraceptive method when evaluated (all low-risk families). Berquó et al. (1977) reported that $28 \%$ of the women in the municipality of São Paulo were not using contraceptives. Thus, there was a much greater concern about birth control in our sample than in the São Paulo population. When our data for different contraceptive methods was compared to that reported by Berquó et al. (1977) for the municipality of São Paulo (Table V), marked differences were observed, always in terms of use of safer contraceptive methods in our sample, e.g., contraceptive pill in our sample $=26.3 \%$ compared to $7.6 \%$ in the sample reported by Berquó et al. (1977); tubal ligation $=16.5 \%$ in our sample and $9.6 \%$ in the sample reported by Berquó et al. (1977). When the frequencies (Table V) are compared between high- and low-risk individuals, it can be clearly seen that risk of repetition had a strong influence especially in terms of greater use of medical contraceptives by the high-risk group (35.3\%) compared to the lowrisk group $(14.1 \%)$. When our sample is compared to those of Carter et al. (1971) and Emery et al. (1973), it can be seen that the frequency of vasectomy among high-risk individuals was higher in our sample $(5.9 \%)$ than in the sample of Carter et al. (1.8\%). Furthermore, the frequency of tubal ligation among high-risk individuals was higher in our sample (26.5\%) than in the sample of Carter et al. $(15.6 \%)$ and lower than in the sample of Emery et al. $(31.1 \%)$. A large number of individuals in our sample (40.6\%) consider their religion to be fully against contraception, which is not true. The present study clearly shows what Berquó et al. (1977) had already reported for São Paulo, i.e., even though religions limit the use of certain 
contraceptive methods, their followers, practicing or not, allege legitimacy of their use, listing economic factors, woman's health and number of existing children as reasons. In our sample there was a strong correlation between acceptance of tubal ligation and the number of women who actually submitted themselves to the procedure. Similarly, among the fathers there was a lower acceptance of vasectomy and a lower effective use of the procedure.

\section{Acceptance of abortion}

Despite the fact that most people (71\%) thought their religion is fully against abortion, most high-risk people in our sample declared that they would accept the interruption of pregnancy in the case of prenatal diagnosis of a severe disease in the conceptus, thus showing the importance of risk of repetition. The frequency of acceptance was significant at the 5\% level and more marked among fathers. This fact should be emphasized because our sample consisted mainly of Catholics who, as reported by Berquó et al. (1977), are considerably influenced by the position of the Church against abortion. However, as also emphasized by the same authors, this does not prevent a minority (28.7\%) of women, who define themselves as practicing Catholics, from accepting an ethical attitude formally contradicting their religion, and some women (7.3\%) confessed to having induced an abortion at some time in the past. In our sample, only one couple was in a position to decide and opted for abortion.

\section{Changes in family composition}

Since we did not construct an internal control in the present study, we have no reliable parameters to evaluate birth rate. However, an approximation can be obtained by comparing the ratio of children born to high- and lowrisk families in our sample and other reports in the literature. In our sample, this ratio was 0.13 for high-risk families (five children born to 36 high-risk families) and 0.50 for low-risk families (35 children born to 69 low-risk families). In the various reports in the literature, this ratio ranged from 0.24 to 0.67 for high-risk families (our 0.13 value was the lowest) and from 0.4 to 0.84 for low-risk families (our value was 0.50 , i.e., only higher than the 0.40 ratio obtained by Abramovsky et al. (1980). Thus, it is our impression that our family sample practiced a considerably high level of birth control after GC, especially high-risk cases, in agreement with the reproductive decisions and the high use of contraceptive methods.

\section{Health situation of the children born}

The rate of repetition of the same disease among high-risk families ranges from 0 to $25 \%$ in the literature. In our sample there was a recurrence rate of $44.4 \%$ in highrisk cases. In low-risk families, the recurrence rate reported in the literature ranges from 0 to $4 \%$. In our sample, the rate of recurrence for low-risk couples was $0 \%$; however, $12.9 \%$ of the children born (four children in 31 families) had another disease differing from that of the propositus. This has been previously reported in the literature (see, for example, Klein and Wyss (1977) who reported a 5.6\% rate and Briard et al. (1977) who reported a $4.4 \%$ rate).

\section{Evaluation of the acceptance of adoption}

In our sample there was a low acceptance of adoption, with only three children being adopted by two out of 36 high-risk families (8.3\%). Other investigators have reported much higher adoption rates: Carter et al. (1971) reported adoption by $21.1 \%$ of high-risk families and $8.3 \%$ of low-risk families; Reynolds et al. (1974) reported adoption by $13.8 \%$ of high-risk families and $1.4 \%$ of low-risk families.

\section{Evaluation of separation of the couples}

In our sample, the frequency of separation was low (two couples in $113=1.7 \%$ ), as opposed to literature values ranging from 3.8 to $6.6 \%$ (Carter et al., 1971; Reynolds et al., 1974; Klein and Wyss,1977; Briard et al., 1977).

\section{CONCLUSIONS} clusions:

The present study led to the following general con-

a) Most families were not spontaneously motivated for GC, with a positive correlation between spontaneous GC motivation and social class.

b) A low understanding (or verbalization) level of the information supplied during $\mathrm{GC}$ was observed. The main factor related to the low understanding level was socioeconomic and cultural level.

c) There was a marked predominance of decisions to avoid pregnancy after GC, also present among individuals at low genetic risk. The risk of repetition was the most important factor in the reproductive decision of the families, followed by number of existing children and social class as secondary factors.

d) A high use of contraceptives was observed, especially in families at high genetic risk.

e) A low birth rate was observed in the families after GC, especially among those at high genetic risk.

f) Rates of adoption and couple separation after GC were low.

\section{ACKNOWLEDGMENTS}

We are grateful to the Hospital das Clínicas, Faculdade de Medicina de Ribeirão Preto, USP, for their support of the Medical Genetics Service. We are also grateful to Dr. Iris Ferrari, Isaias Pessotti, Henrique Krieger and José Carlos M. Pereira for their help during this research and to Conselho Nacional de 
Desenvolvimento Científico e Tecnológico (CNPq) and Fundação de Amparo à Pesquisa do Estado de São Paulo (FAPESP) for financial support. Publication supported by FAPESP.

\section{RESUMO}

Neste trabalho tivemos por objetivo geral a avaliação do impacto do aconselhamento genético (GC) nas famílias atendidas no ambulatório de Genética do HC, FMRP, USP. Foram estudadas 113 famílias atendidas há no mínimo 2 anos e meio e no máximo há 7 anos no Serviço. O método utilizado foi o de entrevista ambulatorial através de formulário constituído por 48 perguntas; as crianças nascidas após o GC foram avaliadas clinicamente. As famílias foram avaliadas em relação à motivação espontânea para o processo de GC, quanto ao entendimento das informações do GC, às suas decisões reprodutivas, modificações na constituição da família após o GC, e, também, quanto à saúde das crianças nascidas após o GC. Foi observado que a maioria das famílias atendidas no HCRP não são motivadas espontaneamente para o GC, que apresentam um baixo nível de entendimento (e/ ou verbalização) das informações recebidas, que as famílias estão na maioria evitando filhos (mesmo as em baixo risco genético), tendo conseqüentemente uma baixa taxa de gravidez e de crianças nascidas após o GC. Estas famílias apresentaram, também, baixas taxas de adoção de crianças e separação de casais, quando comparadas a trabalhos semelhantes.

\section{REFERENCES}

Abramovsky, I., Godmilow, L., Hirschhorn, K. and Smith Jr., H. (1980). Analysis of a follow-up study of genetic counseling. Clin. Genet. 17: $1-12$.

Andrade, M.G.G. and Pereira, J.C.M. (1979). Relatório final referente à bolsa de iniciação científica da FAPESP.

Berquó, E.B. and Camargo, C.P.F. (1977). Diferenciais de Fertilidade. Cadernos CEBRAP. Editora Brasileira de Ciências, São Paulo.

Berquó, E.B., Oliveira, M.C.A.F. and Camargo, C.P.F. (1977). A Fecundidade em São Paulo. Características Demográficas, Biológicas e Sócio-Econômicas. CEBRAP, Editora Brasileira de Ciências, São Paulo.

Boltanski, L. (1979). As Classes Sociais e o Corpo. Edições Graal Ltda.,
Rio de Janeiro.

Briard, M.L., Frézal, J. and Kaplan, J. (1977). Le conseil genetique (resultats de dix années d'expérience). IV. Comportement des consultants et fiabilité du conseil. J Génét. Hum. 25: 157-176.

Carter, C.O., Fraser Roberts, J.A., Evans, K.A. and Buck, A.R (1971). Genetic clinic. A follow-up. Lancet 1: 281-285.

Clarke, A., Parsons, E. and Williams, A. (1996). Outcome and process in genetic counseling. Clin. Genet. 50: 462-469.

Delamothe, T. (1994). Using outcome research in clinical practice. Brit. Med. J. 308: 1583-1584.

Emery, A.E.H., Walt, M.S. and Clack, E.R. (1972). The effects of genetic counseling in Duchenne muscular dystrophy. Clin. Genet. 3: 147-150.

Emery, A.E.H., Walt, M.S. and Clack, E. (1973). Social effects of genetic counseling. Brit. Med. J. 1: 724-726.

Evers-Kiebooms, G. and van den Berghe, H. (1979). Impact of genetic counseling: A review of published follow-up studies. Clin. Genet. 15: 465-474.

Fundação Instituto Brasileiro de Geografia e Estatística (IBGE-1980). IX Recenseamento Geral do Brasil. Vol. 1 - Tomo 4 - No 1.

Guidi, M.L.M. and Duarte, S.G. (1969). Um esquema de caracterização sócio-econômica. Rev. Bras. Est. Pedag. 52: 65-83.

Klein, D. and Wyss, D. (1977). Retrospective and follow-up study of approximately 1000 genetic consultations. J. Génét. Hum. 25: 47-57.

Leonard, C.O., Chase, G.A. and Childs, B. (1972). Genetic counseling: a consumer's view. New Engl. J. Med. 287: 433-439.

McCrae, W., Cuul, A., Burton, L. and Dodge, J. (1973). Cystic fibrosis: parent's response to the genetic basis of the disease. Lancet II: 141-143.

Mussia, M.M. and Pereira, J.C.M. (1980). Utilização de serviços de saúde segundo estratos sociais. Ciênc. Cult. 32: 66 (Abstract).

Reiss, J.A. and Menashe, V.D. (1972). Genetic counseling and congenital heart disease. J. Pediat. 80: 655-656.

Reynolds, B., Puck, M.H. and Robinson, A. (1974). Genetic counseling: an appraisal. Clin. Genet. 5: 177-187.

Shaw, M.W. (1977). Review of published studies of genetic counseling: A critique. In: Genetic Counseling (Lubs, H.A. and Cruz, F. de la, eds.). Raven Press, New York, pp. 35-52.

Sibinga, M.S. and Friedman, C.J. (1971). Complexities of parental understanding of phenylketonuria. Pediatrics 48: 216-224.

Somer, M., Mustonen, H. and Norio R. (1988). Evaluation of genetic counseling: recall of information, post-counseling reproduction, and attitude of the counselees. Clin. Genet. 34: 352-365.

WHO Genetic Counseling (1969). Third Report of the WHO Expert Committee on Human Genetics. World Health Organization Technical Report. Series No. 416, Geneva, Switzerland.

(Received March 19, 1998) 
